\title{
RUY BELO: CORPO DE SI, CORPOS DE OUTREM
}

\section{RUY BELO: BODY OF SELF, BODY OF OTHERS}

\author{
Aline Duque Erthal ${ }^{1}$
}

\section{RESUMO}

A passagem do tempo é uma das linhas de força da poesia de Ruy Belo. O envelhecer inscreve marcas de morte na materialidade dos sujeitos e do mundo, em um processo lutuoso e inelutável. Neste artigo, teceremos alguns comentários sobre o corpo do homem enquanto lugar privilegiado da ética beliana, configurando-se como espaço crítico e de crítica, de denúncia da exploração econômica, social ou política, e mais do que isso: é na abertura ao rosto do outro que persiste, mesmo depois d'Aquele grande Rio Eufrates, um acreditar. Dessa forma, estar no mundo e com outrem - corporalmente - ultrapassa a contingência e se assume como uma responsabilidade.

PALAVRAS-CHAVE: Poesia portuguesa; Ruy Belo; corpo.

\begin{abstract}
The passage of time is one of the lines of strength of Ruy Belo's poetry. The aging process inscribes marks of death in the materiality of the subjects and of the world, in a mourning and ineluctable progress. In this article, we'll make some comments about how the human body is a privileged place in Belian ethics, working as a critical space for denunciation of economic, social or political exploitation, and even more than that: it's trough the overtoure of the subject to the other's face that a belief may subsist, even after Aquele grande Rio Eufrates. Therefore, being in the world and with others - corporately - surpasses contingency and turns to be a responsibility.
\end{abstract}

KEYWORDS: Portuguese poetry; Ruy Belo; body. 
No texto "Breve programa para uma iniciação ao canto", introdução do livro Transporte no tempo, de Ruy Belo, lemos que escrever é "morrer um pouco": "escrevo como vivo, como amo, destruindo-me. Suicido-me nas palavras. [...] Ao escrever, mato-me e mato" (BELO, 2009, p. 367). Toda a vida e o escrever do poeta são um preparar-se para a morte. Mais do que isso: são a própria morte, que se morre todas as horas, minuto a minuto, verso a verso. Morte do corpo que envelhece, morte do sujeito que se esvai progressivamente no escrever:

a minha suprema ambição [...] é a de um simples mineral, com a sua impassibilidade e a sua adesão à terra, a que acabarei por voltar não só por condição como por desejo profundamente, longamente sentido e só satisfeito no dia em que a minha voz passar a ser a voz da terra (BELO, 2009, p. 15).

A minha vida passou para o dicionário que sou. A vida não interessa. Alguém que me procure tem de começar - e de se ficar - pelas palavras. Através das várias relações de vizinhança, entre elas estabelecidas no poema, talvez venha a saber alguma coisa. Até não saber nada, como eu não sei (BELO, 2009, p. 354).

A cada palavra minha eu ia-me esvaziando. Era a vida, a minha vida que se me ia (BELO, 2009, p. 352).

Em outra oportunidade, ${ }^{2}$ já observamos que esse morrer aos poucos e sempre em Ruy Belo produz marcas indeléveis no corpo - sulca, suga, despenca. Discutimos o quanto a materialidade castigada pelo tempo se distancia do ideal romântico de beleza; por outro lado, ela tampouco se identifica com o corpo surrealista nem com o configurado por boa parte da modernidade poética - não se trata de algo monstruoso, espaçado, decomposto em pedaços, desumanizado. "Destrói-se a forma humana, desumaniza-se a arte", escreve Eliane Robert Moraes sobre o corpo moderno (MORAES, 2002, p. 60): esses movimentos não se colam à escrita de Ruy Belo. O sujeito escreve que sua barba cresce "ferozmente", que "Já caem carnes já se perdem pêlos" (BELO, 2009, p. 325); ele tem uma unha incômoda no dedão do pé, "olhar cansado", "calva comprometedora e tendência obesa/ à beira dos 40 anos de idade/ e ajoujado ao peso de vários anos" (BELO, 2009, p. 866); e pode mesmo reduzir-se a uma carcaça, como no verso "Sei que só sou este corpo castigado" (BELO, 2009, p. 656) ou, como veremos adiante, apresentar-se mutilado: ainda assim, esta matéria física é um corpo, que aparece em toda a sua concretude.

A materialidade desgastada pelo tempo manifesta-se no corpo do sujeito e também no alheio. Em especial no masculino, as marcas expõem não apenas o passar dos anos, mas revelam retratos de humilhação, exclusão. Rostos retalhados por rugas do riso (BELO, 2009, p. 217) e expressões corporais como frontes caídas, costas curvas, "pés gretados de homens humilhados" (BELO, 2009, p. 534) são imagens frequentes. O corpo desses homens é espaço crítico e de crítica, de denúncia da exploração econômica, social ou política. Citamos o poema "Não há cavador só do exterior": 
Não há cavador só do exterior

Desgastou-o a terra tornou-se terra

fechou-lhe a boca gretou-lhe a pele

não há cavador só do exterior

Não há cavador só do exterior

Da fome é a sua cor é tão pobre que não conhece o calor a vida mirrou-o o senhor usou-o

não há cavador só do exterior

$[\ldots]$

Não há cavador só do exterior

Arroteou montes fez correr fontes

regos rugas na cara que o choro fura

não há cavador só do exterior

$[\ldots]$

Não há cavador só do exterior

Cava tudo a eito arranca uma pedra tem uma pedra no peito uma lasca de pedra num olho e é já de terra seu corpo velho não há cavador só do exterior

$[\ldots]$

Não há cavador só do exterior

Só tem pele e osso deixou as palavras nos dias de moço foi moço e foi forte mas entranhou-se-lhe no corpo a morte não há cavador só do exterior

(BELO, 2009, p. 649)

O resgate da tradição popular da quadra e as rimas internas embalam no ritmo repetitivo o trabalho do cavador - incessante, de enxada que sobe, enxada que desce, dia após dia, sempre igual. O homem cava a terra e é por ela cavado. Cava a morte, cava para dentro, tem uma pedra no peito. Traz no corpo as cicatrizes de um lavor desumano; arada, sua pele tornou-se terra.

De olhos fitos em outrem, a poesia exerce a resistência possível. Estar no mundo e com os outros - corporalmente - ultrapassa a contingência e se assume como uma responsabilidade. As inter-relações múltiplas e que não cessam de ser processadas entre eu/eu, eu/outro, eu/mundo refletem e implicam um engajamento ético:

\section{SAUDAÇÃO A UM YANKEE}

A perna americana que decerto sem consentimento teu deixaste em território vietnamita e tão visivelmente dificulta agora não já a tua condição itinerante neste mundo mas apenas talvez estar melhor de pé caminhar pela rua afirmar vertical teu tronco como simples árvore a tua perna ó homem com quem nunca falei mais que através de rápidos e talvez ríspidos olhares 
Sou este simples homem olho e envelheço mas tenho duas pernas que mais sinto até quando me doem e sei que as tenho e sei que são exactamente duas porque acabo mesmo agora (é hora de deitar) de as contar e peço-te perdão por tê-las meu amigo e por afirmar nelas a circulação do sangue e o sangue ser a simples pulsação da vida ó meu amigo que o és só porque às vezes cruzas o olhar comigo (BELO, 2009, p. 530)

\section{UM ROSTO NO NATAL}

no dia de natal eu caminhava

e vi que em certo rosto havia a paz que não havia era na multidão o rosto da justiça um rosto que chegava até junto de mim de nicarágua um rosto que me vinha de qualquer das indochinas num mundo onde o homem é um lobo para o homem

Olhava aquele rosto e nesse rosto via a gente do dinheiro que fugia em aviões fretados e os pés gretados de homens humilhados de pé sobre os seus pés se ainda tinham pés ao longo de desertos descampados Morrera nesse rosto toda uma cidade talvez pra que às mulheres de ministros e banqueiros se permita exercitar melhor a caridade A aparente paz que nesse rosto havia como que prometia a paz da indochina a paz na alma Eu caminhava e como que dizia àquele homem de guerra oculta pela calma: se cais pela justiça alguém pela justiça há-de erguer-se no sítio exacto onde caíste e há-de levar mais longe o incontido lume visível nesse teu olhar molhado e triste Não temas nem sequer o não poder falar porque fala por ti o teu olhar Olhei mais uma vez aquele rosto era natal é certo que o silêncio entristecia mas não fazia mal pensei pois me bastara olhar tal rosto para ver que alguém nascia (BELO, 2009, p. 534)

O comprometimento nasce do olhar para si e para o ao-redor, do ver o rosto do mundo e os rostos dos homens. Do mutilado (e é a perna que lhe falta) ou do cadáver, ergue-se a necessidade de se estar de pé, reivindicar existência, ser percebido. Em ambos os poemas, o corpo alheio reverbera no sujeito. $\mathrm{O}$ outro tem olhos que efetivamente olham, varam a rua 
ou a fímbria da fotografia de encontro aos do eu, e é justamente um olhar afetivo (comprometido) que sobressai como condição de existência do homem (ser, olhar e envelhecer sucedem-se em um mesmo verso do primeiro poema, inseparáveis e afirmadores) e de possibilidade de encontro com o outro. Mais até do que a linguagem verbal, é esse modo de olhar que põe o sujeito em relação com o mundo: "a tua perna ó homem com quem nunca/ falei mais que através de rápidos e talvez ríspidos olhares"; "Não temas nem sequer o não poder falar / porque fala por ti o teu olhar".

A afetividade diminui a distância em relação ao outro ("um rosto que chegava até junto de mim da nicarágua”; "ó meu amigo/ que o és só porque às vezes cruzas o olhar comigo"); ela é a forma de o sujeito experimentar-se e de se relacionar, experimentar o mundo, ${ }^{3}$ e é o rosto do outro o começo da inteligibilidade. Pensamos em Emmanuel Lévinas, para quem a ordem do sentido vem da relação inter-humana, do atendimento ao apelo de dor do outro:

O encontro com Outrem é imediatamente minha responsabilidade por ele. A responsabilidade pelo próximo é, sem dúvida, o nome grave do que se chama amor do próximo, amor sem Eros, caridade, amor em que o momento ético domina o momento passional, amor sem concupiscência. (LÉVINAS, 2010, p. 130).

\section{NO ROSTO DO OUTRO, O ACREDITAR: UM COMPROMISSO}

Nesta vida é que nós acreditamos e no homem que dizem que criaste (BELO, 2009, p. 509)

Na dimensão ética que assume o corpo- de si e de outrem -, circunscreve-se ainda, na poética beliana, a reflexão sobre o lugar de deus. Pois é na abertura à alteridade, ao rosto do outro, que persiste, mesmo depois d'Aquele grande Rio Eufrates, um acreditar, como procuraremos desenvolver a seguir.

Antes, porém, de passarmos à sua produção posterior, saliente-se que mesmo Aquele grande Rio Eufrates, o primeiro livro de Ruy Belo, escrito quando o poeta ainda pertencia à Opus Dei, ${ }^{4}$ é perpassado por questionamentos; já "atravessava uma crise profunda quem aliás sempre viveu em crise" (BELO, 2009, p. 17). Desestabilização que não passou despercebida pelo professor da Unicamp Marcos Aparecido Lopes, que indaga, em seu artigo "A missão de Ruy Belo":

Deve-se tomar Aquele grande rio Eufrates como uma expressão direta de um catolicismo ortodoxo ou devemos escavar no arranjo das metáforas a confirmação de certas crenças e a enunciação de algumas dúvidas a respeito desse sistema de crenças? O texto poético de Ruy Belo destina-se a uma apresentação artística das verdades da fé católica ou há neles 
algum tipo de interlocução tensa, capaz de contribuir com o pensamento teológico e a codificação da experiência do sagrado? (LOPES, 2011, p. 158)

Como não enxergar uma prosaicização do sagrado em versos como: "A tua cruz senhor é pouco funcional/ Não fica bem em nenhum jardim da cidade/ dizem os vereadores e é verdade"; "Submetemos os ombros ao teu peso/ mas há tantos outros pesos pelo dia"; "Queríamos ver-te romper na tarde/ e morrem-nos as pálpebras de sono" ("Poema vindo dos dias", p. 113)? Existe um desalento, o acusar já de uma ruína que pouco combinaria com o fervor esperado de um católico bem instalado em sua fé. Mais alguns versos:

\author{
POEMA COTIDIANO \\ Mas hoje o sol \\ morreu como qualquer de nós \\ Ficou tão triste a gente destes sítios \\ Nunca foi tão depressa noite neste bairro \\ (BELO, 2009, p. 109)
}

\title{
AS DUAS MORTES
}

Cada dia mais morte que morte haverá para nós no fim dos dias? (BELO, 2009, p. 90)

\section{DESENCANTO DOS DIAS}

Não era afinal isto que esperávamos não era este o dia

Que movimentos nos consente?

Ah ninguém sabe como ainda és possível poesia neste país onde nunca ninguém viu aquele grande dia diferente (BELO, 2009, p. 93).

Há já uma crise, uma ausência sentida e posta em evidência; expectativa (por aquele "grande dia diferente") frustrada. Os versos parecem cantar algo que - irremediavelmente - falhou.

Se deus aparece marcada e nomeadamente em Aquele grande rio Eufrates, não deixa de permear todo o restante da obra - ainda que na indagação ou questionamento da existência dele, ou em sua própria ausência, uma vez que o não mencionar um deus que outrora se fez tão presente não pode passar despercebido ou iludir-nos como algo não significativo - na própria epígrafe a esta seção, cujos versos serão repetidos adiante, persiste um $t u$, a quem se dirige o sujeito ${ }^{5}$. Em O problema da habitação (segundo livro de Ruy Belo), lemos um deus "distante como o vento ou a vida" (p. 164), em falta ("É muito triste andar por entre Deus ausente”, p. 162), imóvel (“só por nossa boca fala", p. 153). Em "Haceldama”, um vazio:

Outrora vinha Deus e nós dizíamos:

ouve-se o mar

Ou: há na vida ou no quintal a nosso lado 
crianças a brincar

Agora nenhum gesto nesse alguém começa ou morre

(BELO, 2009, p. 147)

Nesse poema, à constatação de uma ausência segue-se uma encenação do retorno de deus, que caminha sozinho pela cidade, com "inúmeras mãos caídas sem remédio ao lado": "Ungi-o mais - oh! muito mais - humano do que nós/ que saberá levar bem mais do que uma enxada às costas/ e até determinar as qualidades físicas dos sons". Embora postos em questão, deus, seu amor e sua palavra não constituem uma renúncia definitiva. Uma busca persiste, incansável, por toda a obra de Ruy Belo - e a relação eticamente responsável com o outro homem (na qual a poesia é um dos utensílios, uma voz a reivindicar a máxima atenção) assoma como o local privilegiado para esse procurar: "Só há lugar, se é que há, para algum humanismo", diz-nos o poeta (BELO, 2009, p. 251).

Voltando ao artigo "A missão de Ruy Belo", de Marcos Lopes, lemos as seguintes observações a respeito dos poemas "Teoria da presença de deus" e "A missão das folhas", do primeiro livro de Ruy Belo:

o que abre a compreensão para o nosso ser é a afirmação de que "somos seres olhados". Portanto, somos convocados a um tipo de alteridade na qual a visibilidade e a acústica são as duas faces da mesma moeda, ou melhor, são dois modos interdependentes de conhecimento da existência humana (LOPES, 2011, p. 160).

Assim como o vento é definido a partir de sua presença nas folhas (folha/vento), do mesmo modo a definição e a presença de deus se dão nos gestos humanos (homem/Deus). A dimensão da alteridade, posta no poema "Teoria da presença de Deus", coloca-se novamente aqui no par folha/vento. (LOPES, 2011, p. 161).

Se a poesia de Ruy Belo não é a da fé transcendental, menos ainda é a da desistência: na relação do sujeito com os outros, persiste a possibilidade de alguma crença. Lévinas, ao se referir à passagem bíblica Mateus 25, observa que a relação com deus ali se apresenta como relação com o outro homem. "Não é metáfora: em outrem, há presença real de Deus", salienta, para em seguida reforçar a realidade dessa presença - no sentido literal e material: "Na minha relação a outrem, escuto a Palavra de Deus. Não é metáfora, não é só extremamente importante, é verdadeiro ao pé da letra. Não digo que outrem é Deus, mas que, em seu Rosto, entendo a Palavra de Deus" (LÉVINAS, 2010, p. 137).

No rosto do outro, a palavra de deus: não seria este o movimento de busca que percebemos, em especial em certos poemas de Homem de palavra (s), como "Os estivadores" (BELO, 2009, p. 282)?

Só eles suam mas só eles sabem

o preço de estar vivo sobre a terra

Só nestas mãos enormes é que cabem

as coisas mais reais que a vida encerra 
Outros rirão e outros sonharão

podem outros roubar-lhes a alegria

mas a um deles é que chamo irmão

na vida que em seus gestos principia

Onde outrora houve o deus e houve a ninfa

eles são a moderna divindade

e o que antes era pura linfa

é o que sobra agora da cidade

Vede como alheios a tudo o resto

compram com o suor a claridade

e rasgam com a decisão do gesto

o muro oposto pela gravidade

Ode marítima é que chamo à ode

escrita ali sobre a pedra do cais

A natureza é certo muito pode

mas um homem de pé pode bem mais

A terceira pessoa coloca o poeta na posição de quem assiste; volta os olhos para o outro. E é do suor, mãos, gestos desse outro que algo se ergue e se funda: realidade, vida, claridade. Afirma-se um poder, uma dimensão principiadora, alicerçada em uma crença - que, sim, persiste; não mais naquele deus transcendental de outrora, mas no (com) homem. Diz-nos "Nós os vencidos do catolicismo":

Nós que perdemos na luta da fé não é que no mais fundo não creiamos mas não lutamos já firmes e a pé nem nada impomos do que duvidamos

$[\ldots]$

Nesta vida é que nós acreditamos e no homem que dizem que criaste se temos o que temos o jogamos "Meu deus meu deus porque me abandonaste?" (BELO, 2009, p. 271)

"Aos homens do cais", "Uma vez que já tudo se perdeu", "Lucas, 21, 28" (os dois últimos, mais em tom de convocação do que de constatação): são numerosos os poemas de Homem de palavra (s) que reivindicam para o homem (outro; ele ou tu) um papel que já fora de deus.

É notória a frequência com que citações bíblicas aparecem nos textos dos diversos livros. Mas é marcante, também, além da seleção desses fragmentos, a forma como são retrabalhados pelo poeta: não como dogmas, conceitos ou lições exemplares, mas como problematização do sujeito e de sua relação com o mundo. Tecem-se parábolas de fissuras e perdas, que não apontam para uma direção a ser seguida, mas para um caminho enovelado sobre si mesmo. Vejamos versos do poema "Imaginatio locorum": 
Como saber de mim? Eu - que diabo! apesar de estrangeiro atrás da face pelo tempo atribuída e de enxertado em oliveira e zambujeiro talvez ainda tenha algumas tias (BELO, 2009, p. 144)

O poema faz referência a um fragmento de Romanos XI. ${ }^{6}$ A passagem bíblica usa a imagem da enxertia para tratar da "severidade" e da "bondade" de deus, e da necessidade de os homens não se vangloriarem contra os outros, mas exercitarem a gratidão e a humildade fraterna. Aqui, interessa-nos o que pode haver de não reconhecimento do sujeito em seu próprio corpo (individual ou social ${ }^{7}$ ), sempre sendo um enxerto; e, por outro lado, o sentido de uma unidade que, ainda assim (ou seja, apesar do hibridismo), é capaz de perseverar. "Sem alteridade não há unidade", adverte-nos o próprio Ruy Belo (2009, p. 846), e no plano ético isso se torna ainda mais visível, uma vez que o poeta em diversas oportunidades reafirma um ideal da comunhão dos homens.

Assim, se não podemos falar na poética beliana como identificação entre sujeito e mundo (sequer entre o sujeito e si mesmo), é legítimo pensá-la como encontro. Não no sentido de achamento, descobrimento ou solução do que quer que seja, mas de pôr-se - voluntária, consciente e fisicamente - em contato com. ${ }^{8}$ Essa é a responsabilidade reafirmada em versos e textos críticos de quem faz do desassossego, compromisso:

Escrever é desconcertar, perturbar e, em certa medida, agredir [...].

É claro que falo do poeta e não do poetastro, do industrial e comerciante de poemas, do promotor da venda das palavras que proferiu.

Falo do homem que nunca repousou sobre o que escreveu, que se recusou a servir-se a si e a servir, que constantemente se sublevou. Falo do homem que, ombro a ombro com os oprimidos, empunhando a palavra como uma enxada ou uma arma, encontrou ou pelo menos procurou na linguagem um contorno para o silêncio que há no vento, no mar, nos campos. O poeta, sensível e até mais sensível porventura que os outros homens, imolou o coração à palavra (BELO, 2009, p. 367).

\section{REFERÊNCIAS BIBLIOGRÁFICAS}

BELO, Ruy. Todos os poemas. 3. ed. Lisboa: Assírio \& Alvim, 2009.

COLLOT, Michel. La matière-émotion. Paris: Presses Universitaires de France, 1997.

ERTHAL, Aline Duque. Ruy Belo, corpo lacunar. Temporis [ação] Revista da Universidade Estadual de Goiás, v. 14, n. 2, jul/dez., p. 6-26, 2014.

LÉVINAS, Emmanuel. Ensaios sobre a alteridade. Petrópolis: Vozes, 2010. 
LOPES, Marcos Aparecido. A missão de Ruy Belo. In: ALVES, I. F, MAFFEI, L. Poetas que interessam mais: leituras da poesia portuguesa pós-Pessoa. Rio de Janeiro: Azougue Editorial, 2011.

MAGALHÃES, Joaquim Manuel. Um pouco da morte. Lisboa: Presença, 1989.

MORAES, Eliane Robert. O corpo impossível - a decomposição da figura humana: de Lautréamont a Bataille. São Paulo: Editora Iluminuras, 2002.

\section{Recebido para publicação em 04/03/2017}

Aprovado em 18/04/2017

\section{NOTAS}

1 Doutora em Letras (Literatura Portuguesa) pela Universidade Federal Fluminense (UFF), com bolsa da Capes. Possui mestrado em Letras (Literatura Portuguesa) pela mesma universidade; especialização em Literaturas e Culturas de Língua Portuguesa: Portugal e África, também pela UFF; e graduação em Comunicação Social / Jornalismo pela Universidade do Estado do Rio de Janeiro (Uerj).

\section{Cf. ERTHAL, 2014.}

3 Michel Collot escreve: "Laffectivité n'est done pas un univers subjectif clos sur lui-même, mais une manière de vivre le monde" (COLLOT, 1997, p. 20). Em tradução nossa: A afetividade não é um universo subjetivo fechado em si mesmo, mas uma maneira de viver o mundo.

4 Sobre Aquele grande Rio Eufrates, o poeta escreve: "Todo este livro foi escrito num clima a que não só já não tenho acesso hoje em dia como espero não o voltar a ter” (BELO, 2009, p. 19).

5 Recomendamos a leitura do capítulo dedicado a Ruy Belo no livro Um pouco da morte, em que Joaquim M. Magalhães defende que o que é recusado pelo poeta, depois do desligamento da Opus Dei, é o uso político de deus. "Não há qualquer recusa de Deus enquanto convergência do sentido religioso do homem. Há apenas afirmação de mudança ideológica e, por isso, alteração do uso social da ideia de Deus. Deus usado como hegemonia de um grupo ou classe social equivale, para ele, no plano da recusa, à ideia de partido usado como detentor absoluto da verdade comunitária" (MAGALHÃES, 1989, p. 153). A questão seria "de pertença a um corpo doutrinário (o Cristianismo) e não de presença de um espírito religioso" (MAGALHÃES, 1989, p. 155). Assim, a poesia de Belo permaneceria "a de um homem religioso até o fim. Mas de uma religiosidade torturada, de quem viu deus afastar-se até dele restar apenas a indecisão e a distância” (MAGALHÃES, 1989, p. 155). Sua descrença nunca deixaria de supor uma crença, em uma interrogação para a qual a poesia não oferece solução.

6 "Pois se a rejeição deles é a reconciliação do mundo, que será a sua admissão, senão a vida dentre os mortos? Mas se as primícias são santas, também a massa o é; e se a raiz é santa, também os ramos o são. Porém se alguns dos ramos foram quebrados, e tu, sendo zambujeiro, foste enxertado entre eles, e te tornaste participante com eles da raiz e da seiva da oliveira, não te glories contra os ramos; porém se te gloriares, não és tu o que sustentas a raiz, mas a raiz a ti. Dirás, pois: Alguns ramos foram quebrados, para que eu fosse enxertado. Bem; pela sua incredulidade foram quebrados, mas tu pela tua fé estás firme. Não te ensoberbeças, mas teme; porque se Deus não poupou os ramos naturais, não te poupará a ti. Notai, pois, a bondade e a severidade de Deus: severidade para com aqueles que caíram, mas bondade de Deus para contigo, se permaneceres nessa bondade; doutra maneira também tu serás cortado. Eles também, se não permanecerem na sua incredulidade, serão enxertados; pois Deus é poderoso para os enxertar de novo. Se tu foste cortado 
do natural zambujeiro, e contra a natureza foste enxertado em boa oliveira, quanto mais não serão enxertados na sua própria oliveira aqueles que são ramos naturais?” (Romanos, XI, 15-24).

7 No artigo "Ruy Belo, corpo lacunar", procuramos mostrar como a presença concreta do corpo no mundo se faz mecanismo para dar a ver o que há de falho nessa inscrição, o não pertencimento, o apesar disso, evidenciando uma fratura entre sujeito e mundo e no sujeito em relação a si mesmo. Leiam-se, a este título, os poemas "Nada consta" (BELO, 2009, p. 325) e "Auto-retrato" (BELO, 2009, p. 866), em que a materialidade do sujeito é reafirmada e inscrita em um lugar, um tempo, um determinado esquema social, mas ainda assim permanece sempre uma lacuna: o sujeito jamais se imbrica com a paisagem de forma apaziguadora, e mesmo em relação a si mesmo não é possível reconhecer uma unidade estável e sem falhas. Há sempre o sentido da perda, da falta.

8 Voltamos a pensar em Michel Collot, para quem "le sujet ne saurait accede à une pleine et entière conscience de lui-même dans la transparence d'une purê intériorité. Son ouverture au monde, à l'autre et au langage fait de lui un “étrange en dedans - en dehors". As vérité la plus intime, il ne peut donc la ressaisir par les voies de la réflexion et de l'introspection. C’est hors de soi qu'il peut la trouver. L'é-motion lyrique ne fait peut-être que prolonger ou rejouer ce mouvement qui constamment porte et deporte le sujet vers son dehors, et à travers lequel seul il peut ek-sister et s'ex-primer. C'est seulement en sortant de soi, qu'il coincide avec lui-même, non sur le mode de l'identité, mais sur celui de l'ipséité, qui n'exclut pas mais au contraire inclut l'altérité, comme l'a bien montré Ricoeur" (COLLOT, 1997, p. 32). Em tradução nossa: O sujeito não pode acessar uma plena e inteira consciência de si mesmo na transparência de uma pura interioridade. Sua abertura ao mundo, ao outro e à linguagem faz dele um estranho por dentro - por fora. Sua verdade mais íntima, ele não pode mais recuperar pelas vias da reflexão e da instrospecção. É fora de si que ele pode encontrá-la. A e-moção lírica talvez não faça mais do que prolongar ou repetir o movimento que constantemente porta e deporta o sujeito para o seu fora, através do qual ele pode ek-sistir e se ex-primir. É somente saindo de si que ele coincide consigo mesmo, não como um modo de identidade, mas como ipseidade, que não exlui - ao contrário, inclui - a alteridade, como bem mostrou Ricoeur. 